\title{
Comprehensive Evaluation of Transport Channel Based on AHP Method
}

\author{
_ As Chang-Zhu-Tan Urban Agglomeration for Example
}

\author{
Yishun Tian \\ School of Transport \\ Wuhan University of Technology \\ Wuhan, P.R.China \\ E-mail: athen2003@163.com
}

\begin{abstract}
Facing with the problems of both realizing development of the transportation and restraint of the environment and the resources, this paper analyzes current situation of transportation of Changsha-Zhuzhou-Xiangtan urban agglomeration and makes comprehensive evaluation on transport channel based on AHP. The evaluation indicators and methods provided the appraisal target and the method for the traffic department to make scientific decisions.
\end{abstract}

Keywords - Chang-Zhu-Tan Urban Agglomeration; Transport channel; AHP method; Evaluation

\section{INTRODUCTION}

With acceleration of globalization, urban agglomeration facilitates the intensification of regional economic competition. In order to speeding up the construction of resource-conservation and environment-friendly society, National Development and Reform Commission have already consented to the decision of Changsha-Zhuzhou-Xiangtan urban agglomeration in December 2007. The regional economy of Changsha-Zhuzhou-Xiangtan urban agglomeration has been developed during those years. But it is inevitable that resources occupation, energy consumption and environmental pollution disturbed robust development of regional economy and the improvement of people's living conditions[1].

\section{COMPREHENSIVE EVALUATION FOR TRANSPORT CHANNEL OF CHANGSHA-ZHUZHOU-XIANGTAN URBAN AGGLOMERATION}

\section{A. Index data collection}

Before the comprehensive evaluation of Changsha-ZhuzhouXiangtan urban agglomeration transport channel by Data Envelopment Analysis (DEA), we should selection decision unit according to the actual situation of Changsha-Zhuzhou-Xiangtan. We collected the following eleven main decision unit by the Changsha-Zhuzhou-Xiangtan urban agglomeration comprehensive transportation network characteristic, with Changsha-Zhuzhou-Xiangtan three major cities for node, combined with Channel identification results and on the basis of the main transportation channels trend. The selection of decision making units and numbers are shown in table 4 .

TABLE I. The Selection of Decision MaKing UnITS AND Numbers

\begin{tabular}{l|l|l}
\hline number & \multicolumn{1}{|c}{ Decision unit } & \multicolumn{1}{c}{ Decision making unit location } \\
\hline 1 & Changsha West Channel & Changsha west through Ningxiang \\
\hline 2 & Changsha East Channel & Changsha east through Liuyang \\
\hline 3 & Changsha North Channel & Changsha north direction \\
\hline 4 & Xiangtan West Channel & Xiangtan west through Xiangxiang \\
\hline 5 & Xiangtan to Zhuzhou Channel & Xiangtan to Zhuzhou \\
\hline 6 & Zhuzhou East Channel & Zhuzhou East through Liling \\
\hline 7 & Changsha to Xiangtan Channel & Changsha to Xiangtan \\
\hline 8 & Changsha to Zhuzhou Channel & Changsha to Zhuzhou \\
\hline 9 & Xiangtan South Channel & South direction of Xiangtan \\
\hline 10 & Zhuzhou South Channel & South direction of Zhuzhou \\
\hline 11 & Liuyang and Liling South-North Channel & North-South channel through Liuyang and Liling \\
\hline
\end{tabular}

Establishment of evaluation index system structure was suitable for data envelopment method according to data collection and questionnaire survey and related statistical data after determine decision unit.

\section{B. Index Pretreatment}

We should put the index pretreatment on index data standardization and the standardized processing in order to reflect 
the real situation as far as possible. Preprocessing results are shown in Table 5.

TABLE II. INDEX PREPROCESSING RESULTS

\begin{tabular}{c|l|l|l|l|l|l|l|l|l|l|l}
\hline Decision Unit & 1 & 2 & 3 & 4 & 5 & 6 & 7 & 8 & 9 & 10 & 11 \\
\hline$X_{11}$ & 60 & 69 & 60 & 69 & 83 & 64 & 78 & 62 & 60 & 69 & 60 \\
\hline$X_{12}$ & 69 & 64 & 71 & 60 & 60 & 100 & 65 & 71 & 85 & 96 & 73 \\
\hline$X_{13}$ & 60 & 61 & 74 & 71 & 100 & 70 & 67 & 69 & 66 & 61 & 92 \\
\hline$X_{21}$ & 77 & 82 & 76 & 100 & 96 & 77 & 96 & 70 & 80 & 83 & 89 \\
\hline$X_{22}$ & 60 & 65 & 75 & 100 & 87 & 61 & 81 & 58 & 67 & 72 & 80 \\
\hline$X_{23}$ & 89 & 60 & 82 & 75 & 100 & 82 & 89 & 96 & 89 & 60 & 67 \\
\hline$X_{24}$ & 89 & 100 & 80 & 100 & 100 & 91 & 89 & 100 & 77 & 87 & 100 \\
\hline$X_{31}$ & 80 & 100 & 74 & 100 & 100 & 64 & 70 & 60 & 64 & 97 & 94 \\
\hline$X_{32}$ & 96 & 71 & 96 & 71 & 64 & 85 & 60 & 71 & 100 & 85 & 71 \\
\hline$X_{33}$ & 64 & 80 & 69 & 91 & 89 & 60 & 97 & 75 & 66 & 100 & 97 \\
\hline$X_{34}$ & 65 & 100 & 60 & 65 & 65 & 65 & 60 & 65 & 60 & 65 & 70 \\
\hline$Y_{11}$ & 70 & 68 & 67 & 73 & 83 & 73 & 70 & 71 & 72 & 95 & 100 \\
\hline$Y_{12}$ & 69 & 64 & 71 & 60 & 60 & 100 & 65 & 71 & 85 & 96 & 73 \\
\hline$Y_{13}$ & 89 & 100 & 83 & 79 & 89 & 82 & 60 & 92 & 90 & 90 & 89 \\
\hline$Y_{14}$ & 61 & 63 & 60 & 76 & 68 & 67 & 59 & 74 & 67 & 80 & 72 \\
\hline$Y_{21}$ & 63 & 72 & 64 & 70 & 77 & 64 & 61 & 64 & 60 & 67 & 62 \\
\hline$Y_{22}$ & 71 & 79 & 68 & 84 & 82 & 100 & 66 & 84 & 79 & 76 & 74 \\
\hline$Y_{23}$ & 78 & 98 & 100 & 69 & 87 & 60 & 62 & 93 & 63 & 80 & 71 \\
\hline$Y_{24}$ & 60 & 89 & 79 & 84 & 97 & 66 & 83 & 62 & 86 & 98 & 68 \\
\hline
\end{tabular}

\section{DEA evaluation based on the AHP}

\section{1) Determine the weight}

According to the Changsha-Zhuzhou-Xiangtan urban agglomeration transport channel development influence analysis and relevant experts to issuing questionnaires, we get at all levels of judgment matrix are showed as follows, including judgment matrix of Infrastructure investment index in Table 6, transport channel structure index in Table 7, resources and environment restriction in Table 8, transport efficiency indicators in Table 9, transportation service index in Table 10. Then build Comprehensive index system is showed in Table 11.

TABLE III. FACTORS OF JUdGMENT MATRIX OF INFRASTRUCTURE INVESTMENT INDEX

\begin{tabular}{c|l|l|l|l}
\hline & & \multicolumn{1}{|c|}{$X_{12}$} & \multicolumn{1}{c|}{$X_{13}$} & \multicolumn{1}{c}{ Priority Vector } \\
\hline$X_{11}$ & 1 & 3 & $1 / 2$ & 0.4761 \\
\hline$X_{12}$ & $1 / 3$ & 1 & 2 & 0.2442 \\
\hline$X_{13}$ & 2 & $1 / 2$ & 1 & 0.2797 \\
\hline
\end{tabular}

TABLE IV.

FACTORS OF JUDGMENT MATRIX OF TRANSPORT CHANNEL STRUCTURE INDEX

\begin{tabular}{|c|c|c|c|c|c|}
\hline Factors & $X_{21}$ & $X_{22}$ & $X_{23}$ & $X_{24}$ & Priority Vector \\
\hline$X_{21}$ & 1 & 2 & $1 / 2$ & $1 / 2$ & 0.2178 \\
\hline
\end{tabular}




\begin{tabular}{l|l|l|l|l|l}
\hline$X_{22}$ & $1 / 2$ & & & $1 / 3$ & $1 / 3$ \\
\hline$X_{23}$ & 2 & 1 & 1 & 1 & 0.2346 \\
\hline$X_{24}$ & 2 & 3 & 1 & 1 & 0.2693 \\
\hline
\end{tabular}

TABLE V. FACTORS OF JUdGMENT MATRIX OF RESOURCES AND ENVIRONMENT RESTRICTION

\begin{tabular}{c|l|l|l|l|l}
\hline Factors & \multicolumn{1}{|c|}{$X_{31}$} & \multicolumn{1}{c|}{$X_{32}$} & \multicolumn{1}{c|}{$X_{33}$} & \multicolumn{1}{c}{$X_{34}$} & Priority Vector \\
\hline$X_{31}$ & 1 & $1 / 3$ & 1 & $1 / 4$ & 0.1171 \\
\hline$X_{32}$ & 3 & 1 & 3 & 4 & 0.5773 \\
\hline$X_{33}$ & 1 & $1 / 3$ & 1 & $1 / 2$ & 0.1392 \\
\hline$X_{34}$ & 4 & $1 / 4$ & 2 & 1 & 0.1664 \\
\hline
\end{tabular}

TABLE VI. FACTORS OF JUDGMENT MATRIX OF TRANSPORT EFFICIENCY INDICATORS

\begin{tabular}{c|l|l|l|l|l}
\hline \multicolumn{1}{|c|}{$Y_{11}$} & \multicolumn{1}{c|}{$Y_{12}$} & \multicolumn{1}{c|}{$Y_{13}$} & \multicolumn{1}{c|}{$Y_{14}$} & \multicolumn{1}{c}{ Priority Vector } \\
\hline$Y_{11}$ & 1 & 2 & 5 & 4 & 0.5107 \\
\hline$Y_{12}$ & $1 / 2$ & 1 & 3 & 3 & 0.2831 \\
\hline$Y_{13}$ & $1 / 5$ & $1 / 3$ & 1 & 1 & 0.0924 \\
\hline$Y_{14}$ & $1 / 4$ & $1 / 3$ & 1 & 1 & 0.1018 \\
\hline
\end{tabular}

TABLE VII. FACTORS OF JUdGMENT Matrix OF TRANSPORTATION SERVICE INDEX

\begin{tabular}{c|l|l|l|l|l}
\hline \multicolumn{1}{|c|}{$Y_{21}$} & \multicolumn{1}{c|}{$Y_{22}$} & \multicolumn{1}{c|}{$Y_{23}$} & \multicolumn{1}{c}{$Y_{24}$} & Priority Vector \\
\hline$Y_{21}$ & 1 & 3 & $1 / 2$ & $1 / 4$ & 0.2577 \\
\hline$Y_{22}$ & $1 / 3$ & 1 & 3 & 3 & 0.2474 \\
\hline$Y_{23}$ & 2 & $1 / 3$ & 1 & 1 & 0.1985 \\
\hline$Y_{24}$ & 4 & $1 / 3$ & 1 & 1 & 0.2964 \\
\hline
\end{tabular}

TABLE VIII. COMPREHENSIVE INDEX SYSTEM WEIGHT

\begin{tabular}{|c|c|c|c|}
\hline Category & Target layer & Index layer & Weight \\
\hline \multirow{11}{*}{$\begin{array}{c}\text { Input } \\
\text { Index } \\
X\end{array}$} & \multirow{3}{*}{$\begin{array}{c}\text { Infrastructure } \\
\text { Investment } \\
X_{1}\end{array}$} & Connectivity of Channel Transportation Network $\left(X_{11}\right)$ & 0.4761 \\
\hline & & Social Applicability of Channel Transportation Network $\left(X_{12}\right)$ & 0.2442 \\
\hline & & Intensity of Channel Transportation Network $\left(X_{13}\right)$ & 0.2797 \\
\hline & \multirow{4}{*}{$\begin{array}{c}\text { Transport Channel } \\
\text { Structure } \\
\left(X_{2}\right)\end{array}$} & Suitable Degree of Transportation Network $\left(X_{21}\right)$ & 0.2178 \\
\hline & & Equilibrium Coefficient of Comprehensive Supply $\left(X_{22}\right)$ & 0.2346 \\
\hline & & Matching Degree of Transport Capacity $\left(X_{23}\right)$ & 0.2693 \\
\hline & & Transfer Time $\left(X_{24}\right)$ & 0.2783 \\
\hline & \multirow{4}{*}{$\begin{array}{c}\text { Resources and } \\
\text { Environment } \\
\text { Restriction } \\
\left(X_{3}\right)\end{array}$} & Noise Effect $\left(X_{31}\right)$ & 0.1171 \\
\hline & & Atmospheric Effects $\left(X_{32}\right)$ & 0.5773 \\
\hline & & The Bearing Capacity of Land Resources $\left(X_{33}\right)$ & 0.1392 \\
\hline & & The Bearing Capacity of Energy Resources $\left(X_{34}\right)$ & 0.1664 \\
\hline
\end{tabular}




\begin{tabular}{|c|c|c|c|}
\hline \multirow[b]{4}{*}{$\begin{array}{l}\text { Output } \\
\text { Index }\end{array}$} & \multirow{4}{*}{$\begin{array}{c}\text { Channel } \\
\text { Transportation } \\
\text { Efficiency } \\
Y_{1} \\
\left({ }^{2}\right)\end{array}$} & Channel Passenger Turnover $\left(Y_{11}\right)$ & 0.5107 \\
\hline & & Channel Passenger Density $\left(Y_{12}\right)$ & 0.2831 \\
\hline & & Channel Transportation Speed $\left(Y_{13}\right)$ & 0.0924 \\
\hline & & Safety Index $\left(Y_{14}\right)$ & 0.1018 \\
\hline \multirow{4}{*}{$Y$} & \multirow{4}{*}{$\begin{array}{c}\text { Channel } \\
\text { Transportation } \\
\text { Technology level } \\
Y_{2}\end{array}$} & Channel Flow $\left(Y_{21}\right)$ & 0.2577 \\
\hline & & Channel Capacity $\left(Y_{22}\right)$ & 0.2474 \\
\hline & & Channel Saturation $\left(Y_{23}\right)$ & 0.1985 \\
\hline & & Channel Traffic Flow Density $\left(Y_{24}\right)$ & 0.2964 \\
\hline
\end{tabular}

2) Colligate index of decision making unit

Because the index that we can choose is more, using the DEA method for Changsha-Zhuzhou-Xangtan urban agglomeration transport channel for comprehensive evaluation is certain difficult. Therefore we need to select appropriate comprehensive index and use the comprehensive index to analysis on DEA. The comprehensive index method is as follows:

$$
z_{i}^{k}=\sum_{j} w_{i j} \sigma_{i j}^{k}
$$

$z_{i}^{k}$ on behalf of weight of the first $i$ comprehensive index in the first $k$ decision unit; $w_{i j}$ means weight of the first $i$ comprehensive index in the first $j$ index; ${ }^{k}{ }^{k}$ presents value at comprehensive index $i$ the $k$ decision unit, which is made by standardized of $j$ index.

According to the comprehensive index method and the front of the index of each branch, we can get the index system of comprehensive value as follows in Table 12.

TABLE IX.

COMPREHENSIVE VALUE OF EACH DECISION UnIT INDEX

\begin{tabular}{c|l|l|l|l|l|l|l|l|l|l|l}
\hline $\begin{array}{c}\text { Decision } \\
\text { Unit }\end{array}$ & 1 & 2 & 3 & 4 & 5 & 6 & 7 & 8 & 9 & 10 & 11 \\
\hline$X_{1}$ & 62.20 & 65.54 & 66.60 & 67.36 & 82.14 & 74.47 & 71.75 & 66.16 & 67.78 & 73.36 & 72.13 \\
\hline$X_{2}$ & 79.58 & 77.10 & 78.49 & 93.27 & 96.08 & 78.49 & 88.65 & 82.54 & 78.54 & 75.34 & 84.03 \\
\hline$X_{3}$ & 84.51 & 80.47 & 83.68 & 76.18 & 71.86 & 75.73 & 66.32 & 69.27 & 84.40 & 85.17 & 77.15 \\
\hline$Y_{1}$ & 69.72 & 68.50 & 68.09 & 69.30 & 74.52 & 79.99 & 65.70 & 72.39 & 75.97 & 92.15 & 87.29 \\
\hline$Y_{2}$ & 67.07 & 83.93 & 76.58 & 77.41 & 86.15 & 72.71 & 68.96 & 74.11 & 73.00 & 81.00 & 68.53 \\
\hline
\end{tabular}

3) Solving DEA model

We use DEA model with AHP restraint and by means of system analysis software to solve the value of decision making unit transport channel efficiency index $\theta_{j}^{*}$, the input index of the slack variable ${ }^{-}{ }_{j}^{-}$, output index of the surplus variable ${ }^{s_{j}^{+}}$and the judgement index $\lambda_{j}^{*}$. The results can be seen in table 13 .

TABLE X.

The Results of DEA Model Solving

\begin{tabular}{|c|c|c|c|c|c|c|c|c|c|c|c|}
\hline Decision Unit & 1 & 2 & 3 & 4 & 5 & 6 & 7 & 8 & 9 & 10 & 11 \\
\hline$\theta_{1 j}^{*}$ & 0.89 & 0.98 & 1.00 & 0.95 & 0.94 & 0.97 & 0.99 & 0.96 & 1.00 & 1.00 & 1.00 \\
\hline Scale Effect & Rise & Rise & invariant & Rise & Rise & Rise & Rise & Rise & invariant & invariant & invariant \\
\hline \multirow[b]{3}{*}{ Slack Variable } & 12.7 & 10.8 & 0 & 0 & 0 & 0 & 10.2 & 7.2 & 0 & 0 & 0 \\
\hline & 0 & 0 & 0 & 6.85 & 0 & 0 & 6.8 & 0 & 0 & 0 & 0 \\
\hline & 0 & 0 & 0 & 0 & 0 & 4.36 & 0 & 0 & 0 & 0 & 0 \\
\hline \multirow{2}{*}{$\begin{array}{l}\text { Surplus } \\
\text { Variable }\end{array}$} & 0 & 0 & 0 & 6.1 & 0 & 0 & 0 & 5.4 & 0 & 0 & 0 \\
\hline & 0 & 0 & 0 & 0 & 9.4 & 0 & 0 & 0 & 0 & 0 & 0 \\
\hline
\end{tabular}


We can see transport channel 3, 9, 10, 11 for DEA efficient and the rest of the decision units for non DEA efficient from the table according to DEA validity judgement theorem. That is to say, Changsha North Channel= Xiangtan South Channel= Zhuzhou South Channel= Liuyang and Liling South-North Channel> Changsha West Channel> Changsha East Channel> Xiangtan West Channel> Xiangtan to Zhuzhou Channel> Zhuzhou East Channel> Changsha to Xiangtan Channel>
Changsha to Zhuzhou Channel in Changsha-Zhuzhou-Xiangtan urban agglomeration transport channel of the relative efficiency. We can find out the difference between input and output index and achieve DEA efficient input and output index by calculating effective front face "projection" of the non DEA efficient decision unit. The specific conditions of Changsha-ZhuzhouXiangtan urban agglomeration transport channel's input and output deficit of each decision unit was shown in table 14.

TABLE XI. INPUT SURPLUS AND OUTPUT DEFICIT SITUATION

\begin{tabular}{|c|c|c|c|c|c|c|c|c|c|c|c|c|}
\hline \multicolumn{2}{|c|}{ Decision Unit } & 1 & 2 & 3 & 4 & 5 & 6 & 7 & 8 & 9 & 10 & 11 \\
\hline \multirow{3}{*}{ Input Surplus } & $\Delta x_{1}$ & 0 & 0 & 0 & 1.2 & 6.5 & 2.1 & 0 & 0 & 0 & 0 & 0 \\
\hline & $\Delta x_{2}$ & 0.31 & 0.24 & 0 & 0 & 2.4 & 0 & 0 & 0 & 0 & 0 & 0 \\
\hline & $\Delta x_{3}$ & 0.94 & 0.78 & 0 & 1.2 & 0 & 1.4 & 2.4 & 2.2 & 0 & 0 & 0 \\
\hline \multirow{2}{*}{ Output Deficit } & $\Delta y_{1}$ & 10.2 & 9.8 & 0 & 0 & 1.4 & 1.3 & 11.5 & 10.8 & 0 & 0 & 0 \\
\hline & $\Delta y_{2}$ & 9.4 & 8.5 & 0 & 2.5 & 0 & 0 & 8.7 & 9.5 & 0 & 0 & 0 \\
\hline
\end{tabular}

\section{RESULTS}

Input surplus and output deficit provides direction for improving the channel service level, raising the level of technology and strengthening the internal rational configuration of decision unit. We can safely draw a conclusion combined with input surplus and output deficit situation and related index weight.The traffic conditions of main line are poor. The join between comprehensive transportation channel and comprehensive transportation hub is backward. The traffic hub's function of highway, railway, airport, waterways and so on in Changsha-Zhuzhou-Xiangtan Urban Agglomeration needs a further review. It is the lack of reasonable division and effective cohesion of different mode of transport which reduce the overall efficiency and service quality of the comprehensive transportation system. Railway, highway, shipping, aviation and other transportation modes are self-contained, each other is not closely linked[4], and they do not form a complementary organic whole. It is disconnection between the traffic hub city and traffic inside and outside. They didn't realize the effective cohesion.

\section{ACKNOWLEDGMENT}

This research was supported by the Ministry of Transport Project in the Western Conference under Grant NO. CXKJSF0104-4.

\section{REFERENCES}

[1] Kausik Gangopadhyay,Banasri Basu, "The morphology of urban agglomerations for developing countries: A case study with China," in New Economic Windows, vol.13, 2010, pp. 90-97.

[2] Deli Wang,Chuanglin Fang,Boyang Gao, "Measurement and spatio-temporal distribution of urbanization development quality of urban agglomeration in China," in Chinese Geographical Science,vol.21,2011,pp.695-707.
[3] Amit Kumar, Arvind Chandra Pandey, Najmul Hoda, A.T. Jeyaseelan, "Evaluating the long-term urban expansion of ranchi urban agglomeration, India using geospatial technology," in Journal of the Indian Society of Remote Sensing, vol39,2011,pp.213-224.

[4] Daniel J. Graham, Kurt Van Dender, "Estimating the agglomeration benefits of transport investments: some tests for stability," in Transportation, vol38, 2011, pp.409-426. 